\title{
Efficacy and side effects of mycophenolate mofetil therapy in children with steroid dependent nephrotic syndrome in a tertiary paediatric nephrology centre in Sri Lanka
}

\author{
*H N S Hettiarachchi ${ }^{1}$, M Raja $^{2}$, U I Karunadasa ${ }^{2}$, R S Thalgahagoda ${ }^{2}$
}

Sri Lanka Journal of Child Health, 2018; 48(1): 53-58

\begin{abstract}
Background: Mycophenolate mofetil (MMF) has been shown to be a well-tolerated drug which could maintain prolonged remission in patients with steroid dependent nephrotic syndrome (SDNS). MMF is known to have a steroid sparing effect.
\end{abstract}

Objectives: To determine the effect of MMF in reducing relapses in Sri Lankan children with SDNS and to ascertain the incidence of side effects of MMF in this population.

Method: Children between 1-18 years of age with SDNS who had been treated with MMF for 12 months or more at the paediatric nephrology unit, Teaching Hospital Peradeniya, were selected and reviewed retrospectively. Children who had previously received immunosuppressive therapy other than prednisolone, cyclophosphamide, cyclosporin A, tacrolimus and levamisole and those who were on MMF for indications other than idiopathic nephrotic syndrome were excluded. Children and parents were interviewed and their patient-held health records, including their 'nephrotic syndrome diary' were reviewed. Data were collected twice a week using pretested questionnaires, in the nephrotic syndrome clinic for a period of 8 weeks. Results were analysed using SPSS version 23.

Results: Thirty five children who met the selection criteria were included. Of them $26(74.3 \%)$ were male and $09(25.7 \%)$ were female. The median age was 9.7 years. Mean number of relapses in the year before starting MMF and the year after starting MMF were 3.5 and 1.8 respectively. The reduction in the relapse rate after being on MMF was

\footnotetext{
${ }^{1}$ Accident and Emergency Unit, Sirimavo Bandaranayake Specialized Children's Hospital, Peradeniya, Sri Lanka, ${ }^{2}$ Department of Paediatrics, University of Peradeniya, Sri Lanka

*Correspondence: sandahetti@gmail.com

(Received on 23 April 2018: Accepted after revision on 29 June 2018)

The authors declare that there are no conflicts of interest

Personal funding was used for the project.

Open Access Article published under the Creative

Commons Attribution CC-BY (c) (i) License
}

significant $(\mathrm{p}=0.009)$. Child's age or gender did not impact the relapse rate $(\mathrm{p}>0.05)$. The most common side effect observed was cough (20\%) and the least common ones were abdominal pain, dyspnoea and dizziness $(3 \%)$.

Conclusions: In this study MMF reduced relapse rates of children with SDNS, despite some minor side effects.

DOI: http://dx.doi.org/10.4038/sljch.v48i1.8652

(Key words: Mycophenolate mofetil, relapses, side effects, childhood steroid dependent nephrotic syndrome)

\section{Introduction}

Nephrotic syndrome (NS) is the commonest glomerular disorder in children ${ }^{1}$. Histologically, minimal change disease (MCD) is found in about $80 \%$ of childhood $\mathrm{NS}^{2}$. Poor long term outcome is a feature of the less common histological variant known as focal segmental glomerulosclerosis $(\mathrm{FSGS})^{3}$. Although corticosteroids are the first choice of treatment in NS with an initial response rate of nearly $90 \%$, relapses will follow in around $60-90 \%$ of patients who initially respond well ${ }^{4}$. NS ultimately becomes frequently relapsing or steroid dependent in about $20 \%$ to $60 \%$ of patients, ultimately resulting in poor quality of life of patients and their families ${ }^{4}$. In addition, it complicates the treatment course for the clinician ${ }^{4}$. There are several second line treatment options in this group of patients, amongst which mycophenolate mofetil (MMF) is a relatively new medication $^{5}$.

In steroid sensitive NS (SSNS), irrespective of the treatment, more than $80 \%$ undergo spontaneous long term remission in later childhood ${ }^{6}$. However, until remission, there is a threat posed by the risk of sepsis, thrombosis, malnutrition, dyslipidaemia and hypovolaemia ${ }^{7}$. As such, a paediatrician should balance the benefits versus the toxicity of using steroids and immunosuppressive therapy for a benign condition such as MCD.

Corticosteroids are the first line treatment for $\mathrm{NS}^{4}$. Nonetheless, the majority of children will experience relapses after 8 weeks of oral corticosteroids, with more than $50 \%$ of them 
becoming steroid-dependent in order to maintain remission $^{8}$. High-doses of prednisolone are associated with complications like hypertension, diabetes and behavioural disorders ${ }^{9,10}$. To alleviate adverse effects of steroid toxicity, steroid-sparing drugs like cyclophosphamide, cyclosporine A (CyA), levamisole (LEV) and tacrolimus are prescribed $^{5}$. Though with good response rates, the severe side effects of the cytotoxic agent cyclophosphamide questions its safety in less severe cases ${ }^{11}$. CyA shows increasing relapse rates once treatment is stopped along with the harmful side effects along with the need to monitor blood CyA trough levels ${ }^{12,13}$. Though the immunomodulating agent LEV has a very good side effect profile, it is less efficacious and is only effective in milder forms of the disease ${ }^{14}$.

MMF is a well-tolerated drug which could maintain prolonged remission in patients with SDNS and frequently relapsing nephrotic syndrome (FRNS) $)^{15,16}$. Acting as a selective reversible inhibitor of inosine monophosphate dehydrogenase, MMF inhibits de novo synthesis of purines ${ }^{17}$. MMF has come up as an attractive alternative due to the better safety profile compared to cyclophosphamide and CyA while having a significant steroid sparing ability ${ }^{18}$.

Most literature on the role of MMF in NS comes from the western world, and it is known that Asian children are more susceptible for NS than Caucasian children ${ }^{19}$. Due to the increase in prevalence of infections, especially upper and lower respiratory tract infections, in this part of the world, majority of Sri Lankan children with NS are steroid dependent and suffer from frequent relapses ${ }^{20}$. There is no published literature on the efficacy of MMF in the management of SDNS in Sri Lankan children.

\section{Objectives}

To determine the effect of MMF in reducing relapses in Sri Lankan children with SDNS and to ascertain the incidence of side effects of MMF in this population.

\section{Method}

This single-centre retrospective analytic study was conducted at the Paediatric Nephrology Unit, Teaching Hospital Peradeniya, Sri Lanka. The recruited population included children between ages 1-18 years with SDNS who had been treated with MMF for 12 months or more at the centre. Patients who had previously received immunosuppressive therapy other than prednisolone, cyclophosphamide, cyclosporin A, tacrolimus and levamisole and the ones who were on MMF for indications other than idiopathic NS (lupus nephritis, renal transplant recipients etc.) were excluded.

Child and parent were interviewed when they had their basic observations done by nursing staff before they saw their clinician. Each patient has a health record which they bring each clinic visit, and this document was reviewed for obtaining clinical data for the questionnaire. Quantitative data regarding number of relapses were obtained from the patient held 'nephrotic syndrome diary' which was reviewed alongside the patient held health record. At the clinic, parents were educated and trained to test and record urine protein excretion in this diary daily. Presence of $3+$ proteinuria for three consecutive days was considered a relapse. The side effect profile was evaluated using any reported symptoms or documentation of physical examination at the time of data collection.

Ethical clearance for the study was obtained from the ethical review committee of the Sri Lanka College of Paediatricians (SLCP). Informed consent was obtained from all individual participants and/or parents where appropriate, prior to collecting data. The period of study was from December 2017 to January 2018. The data were analysed using SPSS version 23.

\section{Results}

Clinical data of 35 children between 4.25-18 years who fulfilled the inclusion criteria were analysed $($ median age $=10.0$ years $)$. Of them, $26(74.3 \%)$ were male and $9(25.7 \%)$ were female. The mean numbers of relapses within the year prior to starting MMF therapy and the year after starting MMF therapy were respectively 3.54 and 1.83 (Table 1).

A significant reduction in the relapse rate after being on MMF therapy for at least 12 months was observed $(p=0.009)$. The steroid dose reduced significantly during the year after starting MMF therapy $(p<0.001)$. The age or gender of the children did not have a significant impact on the relapse rate or steroid dose before and after starting MMF therapy $(p>0.5)$.

Other immunosuppressive medications the patients had been on prior to MMF therapy were levamisole (22), cyclophosphamide (07), tacrolimus (04) and cyclosporine (13). 
Table 1: Summary of the descriptive statistics of patient group $(n=35)$

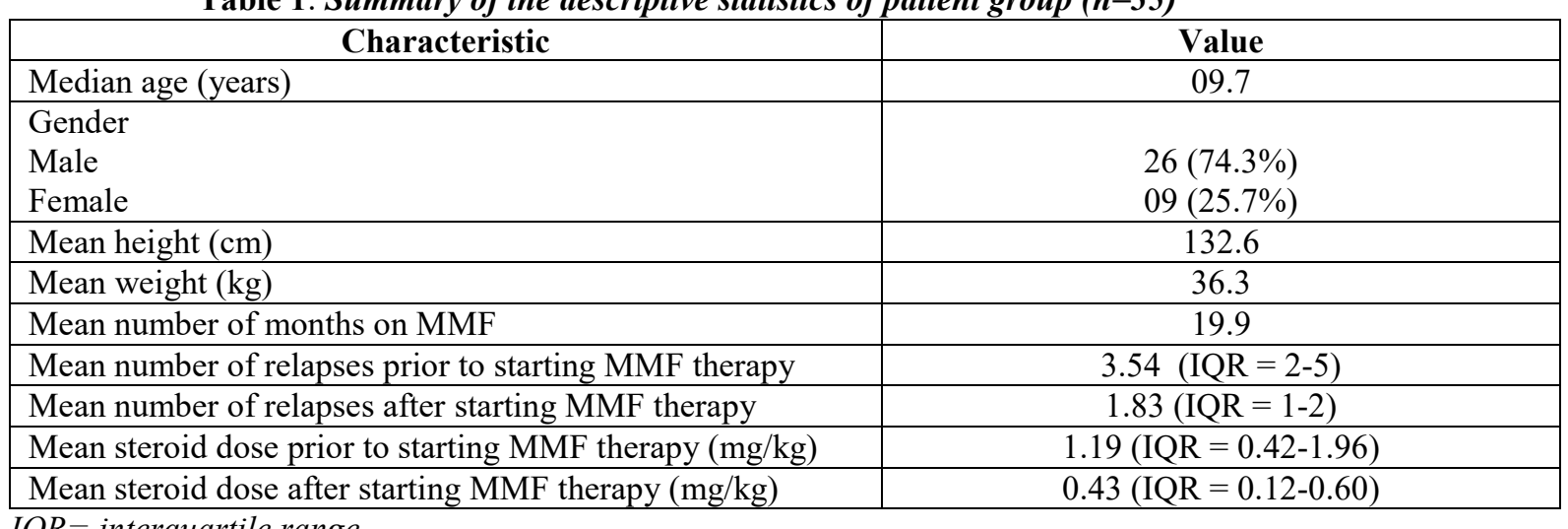

$I Q R=$ interquartile range

Most common side effect was cough $(20 \%)$ and the least common were abdominal pain, dyspnoea and dizziness $(3 \%)$. The side effect profile of the patient group is shown in Table 2 .

Table 2

Side effects encountered in patient group $(n=35)$

\begin{tabular}{|l|c|}
\hline \multicolumn{1}{|c|}{ Side effect } & No. (\%) \\
\hline Abdominal Pain & $01(03)$ \\
\hline Diarrhoea/ Constipation & $03(09)$ \\
\hline GI ulceration/bleeding & $03(09)$ \\
\hline Tachycardia & $02(06)$ \\
\hline Hypertension/ Hypotension & $04(11)$ \\
\hline Cough & $07(20)$ \\
\hline Dyspnoea & $01(03)$ \\
\hline Insomnia & $03(09)$ \\
\hline Tremor & $04(11)$ \\
\hline Dizziness & $01(03)$ \\
\hline Alopecia & $05(14)$ \\
\hline Rash & $01(03)$ \\
\hline Acne & $03(09)$ \\
\hline Infections & $04(11)$ \\
\hline Arthralgia & $06(17)$ \\
\hline
\end{tabular}

\section{Discussion}

Prednisolone was first prescribed for children with NS in 1956, when a study by Arneil reported four children (age 2-8 years), who responded to prednisolone at a daily dose of $60 \mathrm{mg}^{21}$. Although most children respond to steroid therapy, many will subsequently relapse ${ }^{4}$. Children with FRNS or SDNS need individualised treatment and are candidates for an array of immunosuppressive therapy $^{22}$. However, due to the cytotoxicity and other side effects of such drugs, this ideal regimen should have a low side effect profile and be efficient at reducing relapses as well as steroid dependency.

Introduced as a steroid-sparing agent in 1967, different regimens of cyclophosphamide have been used to induce remission with different, but reasonable degrees of success ${ }^{23-26}$. Unfortunately, higher cumulative doses of cyclophosphamide are associated with adverse effects such as haemorrhagic cystitis, alopecia, nausea, gonadal toxicity and risk of future malignancies ${ }^{11}$. A more recent study on SDNS and FRNS patients concluded that only $20 \%$ of children on cyclophosphamide achieved long term remission ${ }^{27}$.

CyA is now used in preference to cyclophosphamide especially in boys who need prolonged immunosuppression, due to the risk of gonadal toxicity ${ }^{28}$. However, unlike with cyclophosphamide, an increased rate of relapse of SDNS has been observed when CyA was discontinued $^{13}$. Though CyA therapy for more than 5 years has achieved sustained remission in children with SDNS, the long-term dosage of CyA poses the risk of serious adverse effects such as nephrotoxicity and malignancy. The former requires regular monitoring of renal function, CyA trough blood levels and sometimes renal biopsies $^{29,30}$.

Levamisole is an immunomodulatory drug with minimal side effects and has shown to be more effective when combined with steroid therapy ${ }^{31}$. Reported side effects include vasculitis, neutropenia, and liver toxicity although there is evidence in existing literature to suggest that these side effects subsided upon discontinuation of levamisole ${ }^{32,33}$. On the contrary, levamisole may not be very suitable in severe cases of SDNS. Similarly, achieving remission using tacrolimus in SDNS has shown varying but not very significant degrees of success ${ }^{8,34}$.

The use of MMF to reduce relapses in childhood NS was first reported in $1999^{35}$. Subsequent studies involving small groups of patients also reported reduced rates of relapses with MMF therapy ${ }^{36,37}$. Bagga et al in 2003 reported reduction in the rate of relapse in 19 children with SDNS. This study stated that there were no significant side effects. However, relapse frequency increased in more than half of the study population after discontinuation of $\mathrm{MMF}^{38}$. Percoraro et al also reported that $82 \%$ of 
children achieving long-term remission in his study where 12 children with SDNS received MMF therapy for a period of 24 months $^{39}$.

More recent literature describes further the beneficial effects of MMF in children who previously received cytotoxic therapy ${ }^{36}$. In 2004 , Gellerman et al published literature showing the efficacy of MMF in inducing and maintaining remission in 7 children who showed both steroid and CyA dependency. All patients already had signs of nephrotoxicity after long courses of CyA. Six of the 7 children remained in remission for the 25 months during which they received MMF. There were no reported adverse side effects or leucopenia ${ }^{40}$. A study by Ulinski et al also concludes that switching from CyA to MMF is safer for children with SDNS and SRNS in terms of disease control as well as side effects ${ }^{18}$. Children with SDNS remained in remission without proteinuria whereas both SRNS and SDNS patients showed a significant increase in GFR.

Our study revealed a statistically significant reduction in relapse rate in patients with SDNS treated with MMF when comparing the relapse frequencies in the year prior to and the year following commencement of MMF. Though one could argue that the natural history of the disease could have had a bearing on the reduction of this relapse frequency, we believe that a reduction of this magnitude could not be attributed to the natural history alone. MMF also proved to be a safe option with only a minimal side effect profile. Interestingly the significant gastrointestinal side effects that plague the transplant population were not seen in our patient. This could be due to the fact that the doses used were significantly lower.

This study revealed 'cough' as the most frequently reported side effect $(20 \%)$ but it must be noted that given the high incidence of recurrent upper and lower respiratory tract infections in Sri Lankan children, it is likely that this is a significant confounder and more likely the cause of the reported incidence of cough, compared to being purely because of MMF. It must also be noted that these children were all steroid dependent therefore side effects such as gastrointestinal bleeds are also difficult to conclude as being solely due to MMF. Overall, there were no serious side effects reported solely from MMF therapy.

\section{Conclusions}

In this study MMF reduced relapse rates of children with SDNS, despite some minor side effects.

\section{References}

1. Eddy A, Symons J. Nephrotic syndrome in childhood. Lancet. 2003; 362(9384):629-39. https://doi.org/10.1016/S01406736(03)141840

2. Carreño A, Morales E, Domínguez-Gil B, Herrero J, Ortiz M, González E et al. The patient with over 100 relapses of minimal change nephrotic syndrome: prolonged complete remission after chlorambucil treatment. Nephrology Dialysis Transplantation 2000; 15(6):922-3. https://doi.org/10.1093/ndt/15.6.922-a

3. International Study of Kidney Disease in Children. The primary nephrotic syndrome in children. Identification of patients with minimal change nephrotic syndrome from initial response to prednisone. Pediatric Nephrology 1981; 98:561-4.

4. Teeninga N, Kist-van Holthe JE, Nauta J. Extending prednisolone treatment does not reduce relapses in childhood nephrotic syndrome. Journal of the American Society of Nephrology 2012; 24:149-59. https://doi.org/10.1681/ASN.2012070646 PMid: 23274956 PMCid: PMC3537218

5. Kim J, Patnaik N, Chorny N, Frank R, Infante L, Sethna C. Second-Line Immunosuppressive Treatment of Childhood Nephrotic Syndrome: A Single-Center Experience. Nephron Extra 2014; 4(1):8-17.

https://doi.org/10.1159/000357355

PMid: 24575119 PMCid: PMC3934602

6. Trompeter RS, Lloyd BW, Hicks J, White RH, Cameron JS. Long-term outcome for children with minimal change nephrotic syndrome. Lancet 1985 ; i: $368-70$. https://doi.org/10.1016/S01406736(85)91387$\mathrm{X}$

7. Thalgahagoda $\mathrm{S}$, Karunadasa U, Kudagammana S, Abeyagunawardena S, Jayaweera H, Abeyagunawardena A. Longterm tapering regimen of prednisolone for the initial episode of nephrotic syndrome. Sri Lanka Journal of Child Health 2017; 46(4):331.

https://doi.org/10.4038/sljch.v46i4.8380

8. Sinha M, MacLeod R, Rigby E, Clark A. Treatment of severe steroid-dependent nephrotic syndrome (SDNS) in children with tacrolimus. Nephrology

Dialysis Transplantation 2006; 21(7):1848-54. https://doi.org/10.1093/ndt/gfi274 PMid: 16311257 
9. Niaudet P. Long-term outcome of children with steroid-sensitive idiopathic nephrotic syndrome. Clinical Journal of the American Society of Nephrology 2009; 4(10): 1547-8. https://doi.org/10.2215/CJN.05950809 PMid: 19808239

10. Hall AS, Thorley G, Houtman PN. The effects of corticosteroids on behavior in children with nephrotic syndrome. Pediatric Nephrology 2003; 18(12):1220-3. https://doi.org/10.1007/s00467-003-1295-x PMid: 14577022

11. Bagga A. Revised guidelines for management of steroid-sensitive nephrotic syndrome. Indian Journal of Nephrology 2008; 18(1):31. https://doi.org/10.4103/0971-4065.41289 PMid: 20368921 PMCid: PMC2847730

12. El-Husseini A, El-Basuony F, Mahmoud I, Sheashaa H, Sabry A, Hassan R et al. Longterm effects of cyclosporine in children with idiopathic nephrotic syndrome: a single-centre experience. Nephrology Dialysis Transplantation 2005; 20(11):2433-8. https://doi.org/10.1093/ndt/gfi059 PMid: 16204303

13. Hulton SA, Neuhaus TJ, Dillon MJ, Barratt TM. Long-term cyclosporin: A treatment of minimal-change nephrotic syndrome of childhood. Pediatric Nephrology 1994; 8:4013.

https://doi.org/10.1007/BF00856512

PMid: 7947023

14. Abeyagunawardena A, Dillon MJ, Rees L, van't Hoff W, Trompeter RS. The use of steroid sparing agents in steroid sensitive nephrotic syndrome Pediatric Nephrology 2003; 18: 919-24.

https://doi.org/10.1007/s00467-003-1216-Z PMid: 12883981

15. Baudouin V, Alberti C, Lapeyraque A, Bensman A, André J, Broux $F$ et al. Mycophenolate mofetil for steroid-dependent nephrotic syndrome: a phase II Bayesian trial. Pediatric Nephrology. 2011; 27(3):389-96. https://doi.org/10.1007/s00467-011-2006-7 PMid: 21947272

16. Hogg R, Fitzgibbons L, Bruick J, Bunke M, Ault B, Baqi N et al. Mycophenolate Mofetil in Children with Frequently Relapsing Nephrotic Syndrome: A Report from the Southwest Pediatric Nephrology Study Group. Clinical Journal of the American Society of Nephrology. 2006; 1(6): 1173-8. https://doi.org/10.2215/CJN.00550206 PMid: 17699344
17. Allison A, Eugui E. Purine metabolism and immunosuppressive effects of mycophenolate mofetil (MMF). Clinical Transplantation. 1996; 10(1 Pt 2):77-84.

PMid: 8680053

18. Ulinski T, Dubourg L, Said M, Parchoux B, Ranchin B, Cochat P. Switch from cyclosporine A to mycophenolate mofetil in nephrotic children. Pediatric Nephrology 2005; 20(4):482-5. https://doi.org/10.1007/s00467-004-1778-4 PMid: 15719253

19. Sharples P, Poulton J, White R. Steroid responsive nephrotic syndrome is more common in Asians. Archives of Disease in Childhood. 1985; 60(11):1014-7.

https://doi.org/10.1136/adc.60.11.1014

PMid: 4073933 PMCid: PMC1777619

20. Abeyagunawardena A, Karunadasa U, Jayaweera H, Thalgahagoda S, Tennakoon S, Abeyagunawardena S. Efficacy of higher-dose levamisole in maintaining remission in steroiddependant nephrotic syndrome. Pediatric Nephrology. 2017; 32(8):1363-7.

https://doi.org/10.1007/s00467-017-3616-5 PMid: 28299461

https://doi.org/10.1007/s00467-017-3616-5 PMid: 28299461

21. Arneil GC. Treatment of nephrosis with prednisolone. Lancet 1956; i: 409-11. https://doi.org/10.1016/S01406736(56)904743

22. Trompeter RS. Immunosuppressive therapy in nephrotic syndrome in children. Pediatric Nephrology 1989; 3(2):218-20. https://doi.org/10.1007/BF00852914

23. Barratt TM, Bercowsky A, Osofsky SG, Soothill JF. Cyclophosphamide treatment in steroid-sensitive nephrotic syndrome of childhood. Lancet 1975; 1(7898):55-8. https://doi.org/10.1016/S01406736(75)910685

24. Ueda N, Kuno K, Ito S. Eight and 12 week courses of cyclophosphamide in nephrotic syndrome. Archives of Disease in Childhood 1990; 65(10):1147-50.

https://doi.org/10.1136/adc.65.10.1147 PMid: 2248508 PMCid: PMC1792340

25. Barratt TM, Cameron JS, Chantler C, Ogg CS, Soothill JF. Comparative trial of 2 weeks and 8 weeks cyclophosphamide in steroidsensitive relapsing nephrotic syndrome of childhood. Archives of Disease in Childhood 1973; 48(4):286-90.

https://doi.org/10.1136/adc.48.4.286 PMid: 4574639 PMCid: PMC1648329 
26. Azib S, Macher M, Kwon T, Dechartres A, Alberti C, Loirat $\mathrm{C}$ et al. Cyclophosphamide in steroid-dependent nephrotic syndrome. Pediatric Nephrology 2011; 26(6):927-32. https://doi.org/10.1007/s00467-011-1830-0 PMid: 21394465

27. Cammas B, Harambat J, Bertholet-Thomas A, Bouissou F, Morin D, Guigonis V et al. Longterm effects of cyclophosphamide therapy in steroid-dependent or frequently relapsing idiopathic nephrotic syndrome. Nephrology Dialysis Transplantation 2010; 26(1):178-84. https://doi.org/10.1093/ndt/gfq405 PMid: 20610527

28. Bargman JM. Management of minimal lesion glomerulonephritis: Evidence-based recommendations. Kidney International 1999; 55(S70):S3-S16. https://doi.org/10.1046/j.15231755.1999.0700 2.X

29. Walker RJ, Tiller DJ, Horvath JS, Duggin GG. Malignant lymphoma in a renal transplant patient on cyclosporin A therapy. Australia and New Zealand Journal of Medicine 1989; 19(2):154-5.

https://doi.org/10.1111/j.14455994.1989.tb002 31.x

30. Kengne S, Massella L, Diomedi F, Gianviti A, Vivarelli M, Greco M et al. Risk Factors for Cyclosporin A Nephrotoxicity in Children with Steroid-Dependant Nephrotic Syndrome. Clinical Journal of the American Society of Nephrology 2009; 4(9):1409-16. https://doi.org/10.2215/CJN.01520209 PMid: 19628686 PMCid: PMC2736699

31. Abeyagunawardena A, Karunadasa U, Jayaweera H, Thalgahagoda S, Tennakoon S, Abeyagunawardena S. Efficacy of higher-dose levamisole in maintaining remission in steroiddependent nephrotic syndrome. Pediatric Nephrology 2017; 32(8):1363-7. https://doi.org/10.1007/s00467-017-3616-5 PMid: 28299461

32. Fu L, Chi C. LEV in steroid-sensitive nephrotic syndrome children with steroiddependency and/or frequent relapses. Acta Paediatrica Taiwanica 2000; 41(2):80-4.

PMid: 10927944

33. Bulugahapitiya DT: Liver toxicity in a nephrotic patient treated with levamisole (letter). Archives of Disease in Childhood 1997; 76:289.

https://doi.org/10.1136/adc.76.3.289
34. Supavekin S, Surapaitoolkorn W, Kurupong T, Chaiyapak T, Piyaphanee N, Pattaragarn A et al. Tacrolimus in steroid resistant and steroid dependent childhood nephrotic syndrome. Journal of the Medical Association of Thailand 2013; 96(1):33-40.

PMid: 23720975

35. Bartosh SM. The use of mycophenolate mofetil in children with nephrotic syndrome [Abstract]. Journal of the American Society of Nephrology 1999; 10 :95A

36. Bunchman T, Flynn J, Kershaw D, Barletta G, Smoyer W. Use of mycophenolate mofetil in steroid-dependent and -resistant nephrotic syndrome. Pediatric Nephrology 2003; 18(8):833-7.

https://doi.org/10.1007/s00467-003-1175-4

PMid: 12774223

37. Novak I, Frank R, Vento S, Vergara M, Gauthier B, Trachtman H. Efficacy of mycophenolate mofetil in pediatric patients with steroid-dependent nephrotic syndrome. Pediatric Nephrology 2005; 20(9):1265-8. https://doi.org/10.1007/s00467-005-1957-y PMid: 15942779

38. Bagga A, Hari P, Moudgil A, Jordan S. Mycophenolate mofetil and prednisolone therapy in children with steroid-dependent nephrotic syndrome. American Journal of Kidney Diseases 2003; 42(6):1114-20. https://doi.org/10.1053/j.ajkd.2003.08.011 PMid: 14655181

39. Two years mycophenolate mofetil treatment of childhood steroid dependent and cyclosporin a dependent nephrotic syndrome [Abstract]. Journal of the American Society of Nephrology 2005; 16:557A.

40. Gellermann J, Querfeld U. Frequently relapsing nephrotic syndrome: treatment with mycophenolate mofetil. Pediatric Nephrology 2004; 19(1):101-4. https://doi.org/10.1007/s00467-003-1300-4 PMid: 14753204 